\title{
Letter to the Editor: a Response to "How COVID-19 Transformed Problem-Based Learning at Carle Illinois College of Medicine"
}

\author{
Luke Read' ${ }^{1}$
}

Accepted: 1 March 2021 / Published online: 5 March 2021

(C) International Association of Medical Science Educators 2021

\section{Dear Editor,}

As a PBL tutor and senior medical student, I believe that I can add another perspective to Coiado et al.'s article on the impact of COVID-19 on PBL [1]. Like the authors of this article, I have facilitated my group during periods of inperson and online PBL as the COVID-19 restrictions have waxed and waned. I have also noticed some the differences between these two modalities identified by Coiado et al.; however, our experiences have not been identical.

Similar to Coiado et al. experience, I have observed an increased level of passive participation and questioning from my students during online sessions. This phenomenon may be explained by Ryan and Deci's self-determination theory [2]. The theory explains that three psychological needs must be met for high-quality intrinsic motivation to be present: autonomy, competence, and relatedness. The communication issues presented by online learning such as poor Internet connection, fewer after class interactions, and a weaker sense of a university community have negatively impacted our students' perceived relatedness to their colleagues and the faculty [3]. This may lead to reduced intrinsic motivation during online PBL resulting in reduced engagement and poorer outcomes.

While Coiado et al. explain that the increased level of passive participation can be mediated by a more involved facilitator, I argue that this is not enough as it is not tackling the cause of the problem. University education has historically undervalued the importance of care and relatedness [4].
With the additional barrier of online education, many students are struggling [5]. Educators should strive to develop more authentic educational relationships with their students while striving to make changes in the way universities value relatedness.

\section{References}

1. Coiado OC, Yodh J, Galvez R, et al. How COVID-19 transformed problem-based learning at Carle Illinois College of Medicine. Med Sci Educ. 2020;30:1353-4. https://doi.org/10.1007/s40670020-01063-3.

2. Deci EL, Ryan RM. Self-determination theory, Handbook of theories of social psychology. Sage Publications Ltd; 2012. https://doi. org/10.4135/9781446249215.n21.

3. Hartnett, MK. Influences that undermine learners' perceptions of autonomy, competence and relatedness in an online context. Australas J Educ Technol. 2015; 31. https://doi.org/10.14742/ ajet.1526.

4. Kidd W, Murray J. The Covid-19 pandemic and its effects on teacher education in England: how teacher educators moved practicum learning online. Eur J Teach Educ. 2020;43(4):542-58.

5. Sahu P. Closure of universities due to coronavirus disease 2019 (COVID-19): impact on education and mental health of students and academic staff. Cureus. 2020;12(4):7541. https://doi. org/10.7759/cureus. 7541 .

Publisher's Note Springer Nature remains neutral with regard to jurisdictional claims in published maps and institutional affiliations.
Luke Read

luke.read@uea.ac.uk

1 University of East Anglia, 1 Elizabeth Way, Aylsham, Norwich NR11 6FW, England 